\title{
Garden therapy
}

The world can be divided into two types of people. Outdoors people and Indoors people. In a similar way there are those of us who are gardeners and those who are not particularly interested in gardening or getting their hands into the soil, but who, nevertheless, like the look of a garden and will take a stroll in the outdoors on a sunny day.

For myself, I enjoy two of the great aimless activities of life pottering and watering. Others are deadheading the roses, raking or sitting on the garden bench. I also find leaning on my rake most satisfactory. There are Master Gardeners but I have aspirations to be a Master Rake Leaner. Rake leaning needs the right angle and also some advanced contemplating and gazing skills. Deep thoughts and reveries are optional.

Some of the small satisfactions of life are bringing flowers that you have grown into the house and fetching your own tomatoes, lettuce and coriander for the evening meal's salad.

A few years ago, I had part-time sessions at Town Hill psychiatric hospital and looked after the psychogeriatric unit. One of the wards was among trees near the perimeter of the hospital grounds and was appropriately named Peacehaven. It contained long-term female patients with a variety of psychiatric disorders, such as chronic schizophrenia as well as some patients with severe bipolar mood disorders who were awaiting placement.

The occupational therapist and I decided to create a sensory garden ${ }^{1}$ outside the ward where there was a large tree and a rather run-down area where they kept the dustbins. We cleared the area and dug eight holes in a circle. I then bought eight small shrubs from nurseries and we had a planting ceremony. Eight of the more functional patients were assigned a shrub each and we helped them with the planting and then handed over the care to the individual patients. They made up the labels for the plant names in the occupational therapy unit and painted them different colours.

I then bought a birdbath and a bird feeder and one of the patients who had some neurological deficit and an unsteady gait volunteered to fill the birdbath every day as part of her daily activities' program and another was keen to keep the bird feeder supplied with bread and seed. The garden soon became alive with weaver birds and little brown jobs (LBJs). There was a white concrete table and bench and the small garden was used not only by the patients but also by visiting relatives and by the staff on their breaks for tea and meals.
We planted Butterfly bushes which grow to about five foot or more and produce lots of colourful flowers, which attract butterflies. We also planted a Lion's Ear (Leonotus) which comes out like a minaret with clusters of orange flowers in the late winter. It attracts birds that enjoy its nectar. In isiZulu it is called by the very appropriate name of Utshwala Bezinyoni, which means "the beer of the birds".

The indigenous medicinal shrubs included African Wormwood (artemisia afra) which is used for coughs and colds. It can also be put in socks for the treatment of sweaty feet (but remember to take it out again before putting the socks in the washing machine).

At the side was a small tree with very pungent aromatic leaves. In Afrikaans it is called perdepisboom but I am not going to translate this into English as I know some of the readers have a delicate sensibility to these rather descriptive epithets. It has the more elegant name in English of Horsewood (clausena anisata) and is a natural habitat for the Swallowtail butterfly.

It is interesting to see the eyes of the patients and staff light up when they recognize the smells of the herbs from the crushed leaves. This is known as "bright eyes" therapy used by occupational health workers to aid in connecting with patients with intermediate and advanced dementia.

During medieval times, monasteries and hospitals had physic and medicinal gardens in which they grew curative herbs, and in more recent years there has been an upsurge in these sensory gardens. They are often designed for the visually impaired, disabled patients, the elderly in retirement homes and for children with special needs.

In gardening there is a reward as well in looking after our greatest patient -the planet. I am all for protecting the Big Five but one should also remember that, worldwide, our combined gardens are one of the biggest game reserves in the world and home to the Small Millions.

\section{Reference}

1. Ellis C. A Sensory Garden. South African Medical Journal 2011;101(10):716

Chris Ellis is a family physician from Pietermaritzburg, KwaZulu-Natal

Email: cristobalellis@gmail.com 